\section{PRESSUPOSTOS METAFÍSICOS \\ PARA A FUNDAMENTAÇÃO MORAL EM SCHOPENHAUER}

\author{
METAPHYSICAL ASSUMPTIONS \\ FOR MORAL FOUNDATION IN SCHOPENHAUER
}

MÔNICA SALDANHA DALCOL ${ }^{1}$

(UFSM, Brasil)

ANSELMO PERES ALÓS ${ }^{2}$

(UFSM, Brasil)

\begin{abstract}
RESUMO
A reflexão acerca da natureza da fundamentação da moral possui uma longa trajetória na filosofia. Uma das principais é proposta desenvolvida pelo filósofo alemão Arthur Schopenhauer, que fundamenta a moralidade a partir da compaixão. Nesse artigo, analisaremos quais são os pressupostos metafísicos necessários para a formulação de uma ética da compaixão.
\end{abstract}

Palavras-chaves: fundamentação da moral; Schopenhauer; compaixão

\section{ABSTRACT}

The reflection on the nature of the foundation of morality has a long trajectory in philosophy. We ought to hilight the proposal developed by the German philosopher Arthur Schopenhauer, who bases morality from compassion. In this work, we will analyze what are the metaphysical assumptions necessary for the formulation of an ethics of compassion.

Keywords: Moral Foundations; Schopenhauer; Compassion

\section{A fundamentação da moral}

O problema da fundamentação da moral não possui uma formulação unívoca; a sua acepção mais célebre e comum consiste na investigação do que está na base da moralidade humana, isto é, o que, de fato, responde pela realização de uma ação humana que é considerada como tendo valor ou peso moral: trata-se de um processo intelectual-reflexivo (fundado no reconhecimento de obrigações e deveres morais pela consciência) ou de algum estado 
psicológico de natureza sensível, automático, provocado pela condição de outros seres humanos (tal como abster-se de fazer algo errado por causar sofrimento nos outros). Tal como se revela nessa primeira acepção, o problema da fundamentação da moral consiste no problema de saber o que, dada nossa constituição como seres humanos, garante a orientação da vontade para a realização de ações boas ou morais. Contudo, esse mesmo problema também tem aparecido na tradição filosófica como um problema vinculado à motivação para a ação moral. A motivação moral explica o mecanismo motivador das nossas ações morais, isto é, o que nos incita a realizarmos ações consideradas boas, dotadas de "valor moral". Em outras palavras, o problema, nessa segunda acepção, consiste em saber quais são os estados ou fatores psicológicos que motivam as pessoas a agirem moralmente. É algum preceito racional, como princípio ou algo como um desejo, impulso ou sentimento?

O problema da fundamentação da moralidade abordado aqui tratará das duas acepções mencionadas acima: o problema de saber, por um lado, de qual aspecto de nossa natureza a moralidade advém - se ela é o resultado de nossa natureza racional ou de nossa natureza passional ou sensitiva - e o que nos motiva a agir moralmente (desejos, impulsos, por um lado, ou argumentos e deduções, por outro). Esses dois aspectos estão reunidos na abordagem de Schopenhauer e, muitas vezes, não estão claramente separados. Embora seja dada atenção para a natureza dos motivos próprios para a moralidade, a maior parte de nosso interesse estará voltada para o debate de fundo em torno da disputa entre razão e sentimento como fundamentos da moralidade humana. Nesse sentido, é importante delinear as duas teorias éticas fundamentais em torno do fundamento da moralidade. Por um lado, há aquelas abordagens que afirmam que a moralidade tem como fundamento a razão; aqui pode ser destacada a célebre tradição da ética kantiana e a sua fundamentação da moralidade na racionalidade humana.

Para Kant, o que unicamente pode constituir a moralidade das ações e o valor moral de qualquer coisa não é uma qualidade intrínseca dos objetos ou situações desejadas, nem a adequação destes a quaisquer fins ínsitos na natureza humana, mas unicamente sua relação a uma vontade boa. Ou seja, só é moralmente bom o que puder ser desejado com boas intenções, e o critério para determinação da bondade de tais boas intenções seria a possibilidade de que o assim desejado, e suas consequências, sejam compatíveis com o que toda e qualquer outra pessoa quereria em situação equivalente (imperativo categórico). Por outro lado, há pensadores que negam a possibilidade da moralidade ter como fundamento a razão; aqui encontramos os empiristas britânicos, notadamente David Hume, que sustentou que a razão não tem poder de motivar e tampouco estabelecer as qualidades morais da virtude e do vício. O valor moral resulta, para Hume, de um sentimento de aprovação ou reprovação associado a certas ações 
que, em si mesmas, não possuem valor moral. Schopenhauer também assumiu um modelo moral fundado em uma crítica radical e substantiva do lugar da razão na moralidade, e procurou mostrar que a moralidade depende da compaixão. Ele dedica boa parte de seus escritos sobre a ética para demonstrar que a moralidade envolve uma espécie de "participação" desinteressada do agente a promover a supressão do sofrimento alheio. Só a compaixão é capaz de conter o “gigantesco" egoísmo que responde, entre outros elementos, pelo caráter trágico e miserável de nossa condição. É partindo desse pressuposto que sua ética foi desenvolvida. Para Schopenhauer, a compaixão envolve uma espécie de comportamento moral frente ao mundo e aos outros. É através da experiência da ação compassiva que atravessamos a "casca fenomênica" e somos conduzidos em direção ao descobrimento de uma mesma essência (una e imutável) onde podemos nos referir a todos os seres como na sentença trazida do hinduísmo e tão proferida nos escritos de Schopenhauer - "Tat twam asi", ou seja, "esse vivente és tu" (SCHOPENHAUER, 2005, p. 295).

Como é comum entre os grandes filósofos, o caminho que conduziu Schopenhauer à defesa da compaixão como fundamento da moralidade é longo e intrincado. Ele supõe, em grande medida, o entendimento de teses e conceitos presentes em obras não inteiramente dedicadas à ética e, sobretudo, supõe um conhecimento profundo do seu sistema metafísico. Faremos referência, sempre que necessário, às noções metafísicas e epistêmicas do sistema de Schopenhauer que serão úteis para o entendimento de sua teoria moral. A apresentação dedicada à reconstrução do projeto ético de Schopenhauer foi desenvolvida levando em consideração alguns pressupostos metodológicos a que cabe salientar. O primeiro aspecto pode ser chamado de o princípio da Unidade ${ }^{3}$ :

1) A compreensão do significado ético das ações humanas não pode ser obtida sem o reconhecimento da unidade da metafísica da Vontade, isto é, a proposta de que a compaixão fundamenta a moral está diretamente vinculada à "verdade metafísica" presente em todo o desenvolvimento de sua filosofia. Ética e Metafísica aparecem, portanto, como duas instâncias interligadas, a saber, a ética como parte de um sistema mais amplo e integrador, o qual supõe integralmente sua metafísica da Vontade ${ }^{4}$;

2) Além do aspecto da unidade entre metafísica e ética no sistema filosófico de Schopenhauer, é importante reconhecer os aspectos internos da própria teoria moral de Schopenhauer. A teoria ética de Schopenhauer possui dois campos distintos de investigação: a discussão estritamente ética, isto é, a investigação em torno das 
condições segundo as quais uma determinada ação pode ser considerada boa ou a investigação sobre os princípios do certo e errado, e, por outro lado, a ética composta também da doutrina da redenção, que constitui o estágio final da sua ética - que corresponde à proposta da completa supressão da Vontade - a total negação da vontade de vida. No ensaio "Sobre o fundamento da moral", presente em Os dois problemas da Ética, Schopenhauer trata especificamente da sua fundamentação da moral a partir da compaixão, mas em outros textos relevantes para a ética como Parerga e Paralipomena, assim como no tomo I e II de O Mundo como Vontade e Representação, Schopenhauer apresenta também elementos da sua teoria da redenção.

3) Um terceiro aspecto relevante e externo que deve ser observado é que sua doutrina moral supõe o conhecimento de alguns elementos presentes na ética kantiana. Schopenhauer foi, em muitos sentidos, um seguidor de Kant, e sua teoria moral invoca implicitamente uma série de noções kantianas. No entanto, isto não o exime de formular duras críticas e identificar alguns "erros" cometidos pelo "grande gênio". Porém, não é o nosso objetivo explorar as críticas em relação ao sistema kantiano de um modo geral, mas sim aquelas críticas dirigidas ao sistema moral kantiano (que afetaram mais diretamente aspectos fundamentais da própria fundamentação da moral na compaixão, defendida por Schopenhauer). Nesse sentido, a abordagem das críticas de Schopenhauer a Kant não será completa, mas girará em torno especialmente da função da razão na moralidade e da natureza do imperativo categórico. Um dos aspectos que mais diferencia Schopenhauer de toda tradição moderna é a sua recusa do lugar comum da razão como essência do ser humano.

Para o filósofo a razão, como concerne ao intelecto, é posterior e está subjugada à Vontade. O ser humano, bem como todo universo, dentro do sistema concebido pelo filósofo é essencialmente Vontade ${ }^{5}$. Schopenhauer demonstra, já no livro II de O Mundo como Vontade e Como Representação, que é no ser humano que se concretiza e se efetua a forma mais elevada de objetivação dessa vontade - através do próprio corpo que é a objetivação imediata da Vontade. Essa Vontade nada mais é do que o impulso incessante, irracional e sem finalidade. Schopenhauer vê a metafísica da vontade atuando no campo da filosofia moral com várias consequências relevantes, não apenas como crítica à filosofia kantiana, mas para a sua própria explicação da possibilidade da moralidade através da compaixão. 


\section{A proposta schopenhaueriana}

A doutrina moral de Schopenhauer foi elaborada a partir do influxo das principais teses assumidas em seu sistema metafísico (composto pelos conceitos de Vontade e de Representação; a chamada "dupla visão de mundo", base de sua doutrina metafísica). O principal movimento teórico de Schopenhauer a partir da sua metafísica da vontade resultou, entre outros aspectos, no desenvolvimento de uma filosofia que possui como pano de fundo o pessimismo metafísico ${ }^{5}$ voltado para o desmascaramento da condição humana. Schopenhauer foi, entre os filósofos modernos, aquele que mais se dedicou a desconstruir a imagem do ser humano como substancialmente um ser pensante, oferecendo, em seu lugar, uma natureza humana volitiva e essencialmente desejante. A ênfase nesse aspecto fez com que o pensamento schopenhaueriano fosse identificado com as chamadas filosofias do impulso, ou também com a filosofia da vida. Essa última, segundo Schnädelbach, tomou o conceito de vida "para enfrentar o racionalismo da ilustração e o materialismo mecanicista como expressão da natureza" (2002 p. 177-178). Tendo em vista a ênfase na Vontade e o "enfraquecimento" do poder da razão, Schnädelbach afirma:

Para Schopenhauer o absoluto, a coisa-em-si, é a Vontade, a vontade de viver, a saber, algo cego, irracional, demoníaco inclusive. O autêntico ser não é o ser, senão o impulso, o processo, a obscuridade. A racionalidade, ou seja, a verdade e o bem não pertencem, portanto, à essência do mundo, são apenas epifenômenos. Enquanto a razão, todos os seus elementos: o intelecto, o pensamento e o entendimento vêm da vontade, e dela são apenas instrumentos que preservam e melhoram a vida (SCHNÄDELBACH, 2002, p. 178).

Ao subverter o entendimento clássico e apresentar a razão subjugada à vontade, Schopenhauer contrapõe-se diretamente à boa parte da tradição filosófica ocidental. Ele considera que o fundamento último e razão de ser do mundo e do ser humano não é nenhum tipo de estrutura racional independente, mas uma força cega, orgânica e impulsiva: a Vontade. Esse princípio atravessa todos os seres existentes.

A vontade é a própria coisa-em-si, compreendida como impulso cego e irracional, o que faz com que muitas vezes a peculiar metafísica schopenhaueriana seja vista como uma espécie de "contrametafísica", justamente porque ela tem como objetivo manter-se no solo firme da experiência ${ }^{6}$. De fato, como Schopenhauer estabelece:

A vontade é o primário e originário; o conhecimento é meramente adicionado como instrumento pertencente ao fenômeno da Vontade. Consequentemente, cada ser humano é o que é mediante sua vontade. Seu caráter é originário, pois querer é a base 
de seu ser. Pelo conhecimento adicionado ele aprende no decorrer da experiência o QUE ele é, ou seja, chega a conhecer seu caráter. Ele se CONHECE, portanto, em consequência e em conformidade à índole de sua vontade, em vez de, segundo a antiga visão, QUERER em consequência e em conformidade ao seu conhecer (SCHOPENHAUER, 2010, p. 171).

Historicamente, o advento desse modelo filosófico-interpretativo significou, nas palavras de Sperling, uma "revolução na hierarquização tradicional do intelecto e da vontade" (2010, p. 26):

A tradição européia vê certamente no homem uma essência contraditória, na qual se divide o conflito entre a racionalidade (espírito) e o instintivo (corpo). No entanto, outorga ao espírito ou à razão do animal rationale o princípio determinante não só em virtude de seu domínio, senão também de sua força. Em sua ascensão divina ou em progresso em direção aos valores eternos, o homem tende a dominar seu impulso instintivo e consegue colocar-se em harmonia com a ordem ontológica do ser dado previamente. Schopenhauer rompe com essa imagem do homem que perdurou por 2500 anos. O intelecto não é o lugar originário da vontade. A vontade como coisa em si é a substância inconsciente do ser humano, enquanto o intelecto é o acidente consciente. O racional é dependente e determinado por algo não racional (SPIERLING, 2010, p. 26).

Contudo, o irracionalismo aqui envolvido necessita ser bem entendido. Apesar da defesa do caráter volitivo da natureza humana (e do universo físico como um todo), há um lugar a ser ocupado pela faculdade de razão ${ }^{7}$. Schopenhauer não pretendeu promover uma negação completa da razão, mas sim restringir o seu papel. O redimensionamento da razão é uma das principais consequências de sua "visão de mundo" centrada na Vontade. Por sua vez, os conceitos de Vontade e representação oferecem um retrato, ou imagem completa, de nossa condição. Embora elas sejam dimensões analisadas separadamente em sua obra magna, no fundo, vontade e representação encontram-se "plenas" em cada ser humano. Elas são uma síntese de nossa fragilidade e grandeza; de um mundo que, por um lado, é o mundo da experiência, marcado pela aparência, por outro, se mostra como fruto de uma essência definidora de nós mesmos (microcosmo) e do próprio mundo (macrocosmo):

Cada um se encontra a si próprio como essa Vontade, na qual consiste a essência íntima do mundo, e cada um também se encontra a si mesmo como sujeito que conhece, cuja representação é o mundo inteiro, que só tem existência em relação à sua consciência como seu sustentáculo necessário. Cada um, portanto, é o mundo inteiro nessa dupla acepção, é o microcosmo que encontra as duas partes do mundo completa e plenamente em si mesmo. Aquilo que conhece como próprio ser esgota, em verdade, a essência do mundo inteiro, do macrocosmo, pois o mundo, tanto quanto a pessoa mesma, é absolutamente Vontade e absolutamente representação, e nada mais (SCHOPENHAUER, 2005, p. 228-229). 
É, portanto, a partir dessa dupla acepção entre representação e vontade que a própria teoria ética de Schopenhauer constituir-se-á.

\section{A visão dupla do mundo: representação e Vontade}

A base de todo sistema filosófico schopenhaueriano já pode ser vista explicitamente no título da sua obra magna, O Mundo como Vontade e como Representação. Essa grande obra é dividida em quatro livros, cada um tratando de um tema distinto, porém, como o próprio Schopenhauer afirma, resultam de um único pensamento. É propriamente no Livro I que Schopenhauer apresenta o mundo tal como conhecemos em nossa própria experiência, tendo como ponto de partida o ser que conhece: “o mundo é absolutamente representação, e precisa, enquanto tal, do sujeito que conhece como sustentáculo de sua existência" (2005, p. 75). Esse mundo tendo a forma universal de sujeito e objeto pressupõe a relação de dependência entre ambos os conceitos ${ }^{8}$. Tal mundo é justamente o mundo concreto, empírico, ao qual temos acesso e é palco de toda experiência possível ${ }^{9}$. Segundo Schopenhauer, a constatação de que "o mundo é minha representação" (2005, p. 200) é a única verdade que podemos afirmar a priori: "é ela que exprime o modo de toda experiência possível e imaginável, conceito bem mais geral até que os de tempo, espaço e causalidade que a supõem" (2013, p. 64).

Os dois princípios que regem o mundo como representação são o principium individuationis (princípio de individuação) e o princípio de razão ${ }^{10}$. O princípio de razão atua no conhecimento, buscando compreender a razão dos acontecimentos que se apresentam diante de nós. O princípio de individuação tem implicações diretas para a moralidade (pois será através da sua supressão que se torna possível a ação moral). Tal princípio constitui a forma de qualquer experiência: o espaço e o tempo. É através dele que o mundo se apresenta para nós, marcado pela diversidade, em que aparecem múltiplos fenômenos, como se eles fossem completamente indistintos:

Chamarei, portanto, o espaço e o tempo, segundo uma velha expressão da escolástica, de principium individuationis; pois é por intermédio do espaço e do tempo que o que é um e semelhante em sua essência e em seu conceito aparece para nós como diferente, como vários, seja na ordem da coexistência, seja na sua sucessão (SCHOPENHAUER, 2013, p. 60).

O princípio de individuação é o principal responsável pelo egoísmo, um agente motivador que Schopenhauer considera incompatível com qualquer ação moral genuína. Como explica Cacciola, “é do ponto de vista da representação que existem, pois, indivíduos separados, 
e, aí, o egoísmo se faz presente como o motivo antimoral por excelência" (CACCIOLA, 1994, p. 158).

\section{A Vontade}

A Vontade, como equivalente à coisa em si kantiana, complementa o mundo como representação. “O mundo é minha vontade”, diz Schopenhauer (2005, p. 206). Tal Vontade é em si mesma irracional, marcada pela carência, dado que os seres humanos como expressão de objetivação dessa Vontade, estão inseridos em um jogo de afirmação e negação ou supressão da vontade ${ }^{11}$. Ela possui um "estatuto cosmológico" - ela é a essência regente do mundo ${ }^{12}$, estando presente em todos os fenômenos e possui três características básicas: “ $a$ unidade, a infundamentabilidade e a incognoscibilidade"13.

Como a Vontade é marcada por essas características, no contexto do mundo como vontade, diferentemente do que caracteriza o mundo como representação, não há a forma sujeito e objeto. Por conseguinte, fica vedado o acesso ao conhecimento da vontade, visto que só podemos ter conhecimento a partir do domínio dos fenômenos. Aqui não nos é permitido investigar questões relacionadas ao fundamento, razão ou causa da Vontade. Mas como podemos falar, então, da coisa em si? Qual o sentido de estabelecer uma realidade metafísica significativa para além dos fenômenos? A resposta dada por Schopenhauer avança em direção a uma forma "especial" de "conhecimento", que permitirá a nós termos acesso à dimensão da coisa em si. É justamente esse conhecimento que ele chamará de conhecimento do todo da vida. Esse acesso à vontade é possibilitado pela nossa dimensão corpórea e, posteriormente, é estendido, por meio de analogia, a todos os fenômenos presentes no mundo:

O corpo humano, tomado como Objektität, "objetidade", é o ponto de vista privilegiado para se penetrar no segredo do universo. Pela subjetividade, pode-se sentir a ação corporal como essencialmente volitiva, e, a seguir, concluímos, por analogia, que o mesmo acontece nos outros corpos (BARBOZA, 1997, p. 49).

Assim, é através de nossa natureza corpórea que apreendemos a coisa-em-si (Vontade). Essa mesma vontade exercerá um papel preponderante na teoria moral, pois é a vontade que origina uma caracterização da condição humana bastante pessimista, não só no que diz respeito à possibilidade da ação moral, mas, sobretudo, do potencial humano para desfrutar uma existência feliz e livre. Como o ser humano é mais uma expressão da mesma Vontade que gera o mundo e tudo que há nele, não há, nesse cenário, liberdade. Contudo, essa mesma vontade pode tomar dois caminhos diferenciados - através da sua negação ou afirmação. 


\section{Liberdade}

A liberdade na filosofia de Schopenhauer está restrita à Vontade, que é essencialmente livre. Os seres humanos como expressão dessa mesma vontade são metafisicamente "livres". Como diz Schopenhauer, “o EM SI mesmo é a Vontade e está é integralmente livre por toda eternidade" (2005, p. 372). Já a esfera da representação, onde os seres encontram-se fisicamente determinados, através do princípio de individuação, é regida pela necessidade: cada coisa, como fenômeno, isto é, como objeto, é absolutamente necessária; consequentemente, não há liberdade no campo dos fenômenos. Essa estruturação vale também para o ser humano, que é "o fenômeno mais perfeito da Vontade" (SCHOPENHAUER, 2005, p. 373). Como objetidade, o existente humano é corpóreo; por um lado, ele é capaz de adquirir conhecimento dos fenômenos da vontade, que se encontram no plano da representação.

Por outro lado, ele também se encontra sujeito às regras da coisa em si, sendo, portanto, do ponto de vista desse aspecto, necessariamente determinado. Em outras palavras, a Vontade em si mesma é livre, enquanto o ser humano, como mais um fenômeno determinado por essa Vontade, tem seu querer livre determinado: “e, desde que este entra na forma de todo objeto, o princípio de razão, a pessoa desenvolve de fato a unidade extratemporal daquele querer e sim, expõe a legalidade de uma força natural” (SCHOPENHAUER, 2005, p. 374). Dessa forma, cada ação particular do ser humano é também atribuída à Vontade livre ${ }^{14}$.

Schopenhauer também distingue entre "liberdade da vontade" e a "liberdade de ação", que nada mais são que as capacidades que nós temos de escolhermos fazer algo que queremos. A noção de liberdade da vontade envolve lidar com o problema da liberdade de querer e, ao mesmo tempo, a impossibilidade da consciência fornecer a nós a certeza de se poder ou não ter um desejo diferente daquele que está presente em um determinado momento. A autoconsciência de todos afirma com clareza que a pessoa pode fazer o que lhe aprouver. Mas como, de fato, podemos pensar que a pessoa deseje ações opostas entre si, segue-se que se desejar, a pessoa pode fazer o contrário, mas isso, segundo Schopenhauer, não é evidente ${ }^{15}$.

\section{Caráter}

A concepção schopenhauriana da Vontade produz consequências importantes não só para sua abordagem da liberdade, mas também para noções psicológicas relevantes para a ética, como é o caso do conceito de caráter. Seguindo as consequências de sua metafísica da vontade, 
Schopenhauer toma o caráter em três sentidos: caráter inteligível e sensível e adquirido ${ }^{16}$. $\mathrm{O}$ caráter inteligível, como grau de manifestação da vontade (compreendido como ideia platônica) é inato, isto é, a rigor, não cabe ao ser humano escolher ser de determinado modo; no que concerne à moralidade, não cabe a ele escolher ser "bom" ou "mau". Não há, dessa forma, nenhuma possibilidade de avanço humano em termos morais ou, o que é o mesmo, que um possível melhoramento moral fica, de antemão, descartado. Como afirma Spierling, "a ideia de melhorar o mundo e os seres humanos em conjunto é rejeitada como mera ilusão”. Deste modo, "trata-se de estudar e interpretar metafisicamente sem suavizar o que os homens fazem ou deveriam fazer no reino dos fatos" (SPIERLING, 2013, p. 128).

A teoria do caráter de Schopenhauer foi desenvolvida a partir da célebre solução ${ }^{17}$ oferecida por Kant presente na resolução da terceira antinomia ${ }^{18}$, que trata do problema da liberdade. Schopenhauer usa a distinção kantiana do caráter empírico como "esquema sensível” do caráter inteligível para buscar uma conciliação entre liberdade e necessidade ${ }^{19}$. Ele diz:

Foi, porém, Kant que, primeiro, esclareceu este ponto importante por meio de sua grande doutrina de que o caráter empírico que, como fenômeno, apresenta-se no tempo e numa multiplicidade de ações tem por fundamento o caráter inteligível que é a qualidade da coisa-em-si daquele fenômeno e, por isso, independe do espaço e do tempo, da multiplicidade e da mudança. Só a partir daí torna-se explicável a tão espantosamente rígida imutabilidade dos caracteres experimentada por todos (SCHOPENHAUER, 2001, p. 193).

Schopenhauer toma essa distinção sustentando que o caráter inteligível é a vontade em si e o caráter sensível é a ação no tempo e no espaço (corporificação). Como afirma Debona, “o filósofo está munido de uma concepção de caráter cuja natureza é algo irracional, volitiva, e não mais algo racional, deduzido pela razão, como nos moldes kantianos” (2013, p. 70). O caráter inteligível encontra-se fora do "mundo natural"; ele não é afetado pelas leis causais e, consequentemente, jamais sofrerá qualquer tipo de alteração, pois não há causa que determine a ação, ela é em si mesma livre. No que diz respeito ao caráter empírico, ele é expressão daquele caráter inteligível (imutável) e é somente através dele que temos "contato" com o caráter inteligível. Em o Mundo como Vontade e Representação, o caráter inteligível e o empírico são definidos do seguinte modo:

O caráter inteligível de cada homem deve ser considerado como um ato extratemporal, indivisível e imutável da Vontade, cujo fenômeno, desenvolvido e espraiado no tempo, espaço e em todas as formas do princípio de razão, é o caráter empírico como este se expõe conforme a experiência, vale dizer, no modo de ação e no curso de vida do homem. Assim como a árvore inteira é somente o fenômeno sempre repetido de um único e mesmo impulso, exposto da maneira mais simples na fibra, de novo repetido e facilmente reconhecível na composição da folha, do talo, do 
galho, do tronco, assim também todas as ações particulares do mundo são apenas a exteriorização sempre repetida do seu caráter inteligível (embora possam variar alguma coisa na forma), e a indução resultante da soma dessas ações constitui precisamente o seu caráter empírico (SCHOPENHAUER, 2005, p. 375).

Tendo em vista que o caráter inteligível é inato e constante, é nas ações do indivíduo que sabemos se ele é mau ou bom, as quais manifestarão o caráter inteligível em todas as ações ao decorrer de sua vida:

[...] o que é conhecido como caráter empírico através do desenvolvimento necessário no tempo, e a divisão em ações isoladas resultante de tal desenvolvimento é, abstraindo-se a forma temporal do fenômeno, o CARÁTER INTELIGÍVEL, conforme a expressão de Kant. Este, assim, mostra brilhantemente o seu mérito mortal, especialmente quando demonstra e expõe a diferença entre liberdade e necessidade, isto é, a diferença propriamente dita entre Vontade como coisa-em-si e seu fenômeno no tempo. O caráter inteligível coincide, portanto, com a Ideia ou, dizendo mais apropriadamente, com o ato originário da Vontade que nela se objetiva (SCHOPENHAUER, 2005, p. 221).

Dessa forma, a volição, o querer entendido de modo particular, os motivos próprios do querer, podem ser reconhecidos apenas empiricamente, enquanto que, no que diz respeito à nossa natureza geral, os motivos que estão por trás do querer acabam por ser o que Schopenhauer chama de "mistério". O caráter empírico, por ser individual, difere em cada indivíduo, o que justifica que as pessoas reajam de maneira diferente diante de um mesmo fato. Mesmo que os motivos postos sejam os mesmos, as reações resultantes podem diferir. O caráter empírico, portanto, nada mais é que a própria manifestação daquele caráter inteligível, do qual temos acesso através das ações isoladas, isto é, mediante a nossa própria experiência do agir: "o decurso de vida desenha a imagem do caráter empírico, cujo original é o caráter inteligível" (SCHOPENHAUER, 2005, p. 467).

A tese da imutabilidade do caráter está profundamente relacionada com as características intrínsecas ao próprio sistema schopenhaueriano. Dado que o papel do intelecto é secundário, o mesmo ocorre com relação ao caráter: ele não pode jamais ter "força" para alterar a Vontade; consequentemente, a sua função é meramente suplementar. Cabe a ele "clarear" os motivos que apresentados à consciência no momento da realização da ação. Dessa concepção decorre que o papel do intelecto é restrito à estrutura da ação, resultando em uma espécie de determinismo do querer. Deste modo, o conhecimento de nossa natureza pode ser aprimorado no tempo, mas o querer não é aberto ou de escolha livre pelo ser. Conforme explicita Schopenhauer, "digo que o homem é sua própria obra antes de todo conhecimento, e este é meramente adicionado para iluminá-la. Daí não poder decidir ser isto ou aquilo, nem se 
tornar outrem, mas é de uma vez por todas, e sucessivamente o QUE é” (SCHOPENHAUER, 2005, p. 379).

Essa concepção de caráter produz, naturalmente, consequências para a caracterização da compaixão. Como Schopenhahuer estabelece em Sobre o Fundamento da moral, algumas pessoas agem movidas pelo sentimento da compaixão, e outras não. A explicação dessa diferença radica no determinismo presente no caráter, onde nem mesmo um sentimento "genuinamente puro" poderia alterá-lo:

Pode a ética, já que descobre a motivação moral, fazê-la atuar? Pode ela transformar um homem de coração duro num compassivo e, daí, num justo e caridoso? Por certo não: a diferença dos caracteres é inata e indelével. A maldade é tão inata ao maldoso como o dente venenoso ou a glândula venenosa da serpente (SCHOPENHAUER, 2001, p. 190).

Para reforçar a sua tese acerca da impossibilidade de um progresso moral ou melhoramento humano, ele utiliza três instâncias como forma de legitimar a sua tese: o apoio na autoridade dos antigos, a doutrina originária do cristianismo e, por último, para não deixar sombra de dúvidas, a própria realidade:

Ora, a realidade e a experiência, que sempre se opuseram vitoriosamente às
promessas de uma ética que quer melhorar os homens moralmente e fala de progresso
na virtude, provaram com isso que a virtude é inata e não resulta de pregação. Se o
caráter não fosse, como originário, imutável e por isso impenetrável a toda melhoria
mediante a correção pelo entendimento; se, antes, como aquela ética superficial o
afirma, fosse possível uma melhoria do caráter mediante a moral e, de acordo com
isso, "um constante progresso para o bem", então, se as muitas instituições religiosas
e os esforços moralizantes não tivessem errado o alvo, a metade mais velha da
humanidade teria de ser significativamente melhor do que a mais jovem, pelo menos
na média. Há, porém, tão poucos traços disto que, inversamente, esperamos antes
algo de bom dos jovens do que dos velhos, que ficaram piores com a experiência
(SCHOPENHAUER, 2001, p. 193-194).

\section{Considerações Finais}

A partir dessa visão, fica evidente que a humanidade não está em um "constante progresso para o bem" e nem mesmo prescrições morais teriam sucesso e força frente ao determinismo do caráter inteligível. Porém, há outro aspecto relevante que precisamos destacar é que é justamente aí que reside a responsabilidade de nossos atos. Janaway sintetiza esse ponto da seguinte maneira: 
Se não posso escapar à necessidade causal por ser parte da realidade empírica, um aspecto de mim que está além da realidade empírica pode. Schopenhauer assinala que, quando julgamos alguém responsável por alguma coisa, culpamos o caráter da pessoa, ou aquilo que ela é, usando as ações como mera prova disso. Ele sugere que tenho de ser responsável pelo que sou - meu caráter inteligível que se oculta sob as aparências, do qual vêm todas as minhas ações (JANAWAY, 2003, p. 116-117).

A responsabilização diz respeito à essência e não ao próprio agente, empiricamente falando:

Como o homem é, assim ele deve agir; portanto, não ao seus atos individuais, mas ao seu ser e essência cabem culpa e mérito. Por isso, teísmo e responsabilidade moral são incompatíveis; justamente por que a responsabilidade sempre recai sobre o autor da essência, onde tem o seu centro de gravidade. Em vão se procurou construir uma ponte entre esses dois inconciliáveis, através do conceito de liberdade moral do homem: mas ela sempre cai. O ser livre tem que ser também o ser originário, e viceversa. [...] O simples reconhecimento da estrita necessidade das ações corresponde à doutrina de que também no ser desprovido de conhecimento é a vontade que se manifesta. Senão, na atuação desta necessidade evidente, se disporia a mesma em oposição ao querer, se houvesse efetivamente tal liberdade do agir individual e esta não fosse precisamente necessitada tão rigidamente como todas as outras ações [...]. A mesma doutrina da necessidade dos atos de que foram sorteados (SCHOPENHAUER, 2001, p. 190-191).

A vontade exige que a essência do homem seja obra de sua própria liberdade, portanto de sua vontade que então possui asseidade. Sob a hipótese contrária, como já se demonstrou, desapareceria toda responsabilidade e o mundo moral, assim como físico, seria apenas uma mera máquina, posta em movimento pelo seu construtor situado de fora, apenas para o próprio entretenimento (SCHOPENHAUER, 2012, p. 80-81).

A lógica inexorável de atuação da vontade impõe, nesse sentido, limites à liberdade e define o caráter no plano empírico ou sensível. A equação que Schopenhauer procurará solucionar em sua teoria moral é como guardar espaço, em um mundo governado causalmente e sob as leis da vontade, para a ação moral genuína. Esse problema é uma consequência direta de sua teoria metafísica, pois um mundo determinado e, ao mesmo tempo, compatível com ações de cunho moral é possível. De fato, a dificuldade maior deriva de uma consequência prática imediata da concepção metafísica de Schopenhauer: a amplitude e abrangência do egoísmo em nossa condição. Nós somos, empiricamente falando, seres determinados. Essa determinação é, metafisicamente falando, determinação para um querer regulado pela vontade, por uma vontade de persistir, vontade de vida, impulsiva, que conduz ao conflito e à tentativa de submissão de outras vontades. A determinação imposta pela vontade é, portanto, uma determinação ligada ao egoísmo e funda uma visão pessimista da vida.

Os conjuntos de conceitos apresentados aqui ocupam uma posição especial na filosofia de Schopenhauer e que, por isso mesmo, são relevantes para o estabelecimento das bases da 
sua teoria moral, bem como a dimensão metafísica que faz com que o ser humano seja dirigido por fins como "manter-se vivo" e "reproduzir" ou "produzir vida nova", gerando uma série de objetos de desejo e necessidades correspondentes à ampliação de seu repertório cognitivo e cultural (JANAWAY, 2009). Estamos inseridos nesse modo de existência, marcado cotidianamente pela busca e satisfação de nossos desejos. Esse "jogo" onde perseguimos determinados fins, alternando entre um objeto de desejo e outro (originado da carência, isto é, da falta) é uma das formas em que o sofrimento se apresenta. Como explica Debona, a vontade funda uma

[...] cosmologia da vontade irracional, essência cega e incessante de todos os seres, que faz prevalecer em todo indivíduo um egoísmo colossal, que "comanda o mundo" e desconhece qualquer identidade entre eu e não-eu. Pelo fato de uma tal essência carecer de fundamento e de fins últimos, as satisfações são sempre passageiras e as disputas, os conflitos e as guerras são eternos, do que decorre uma teodiceia (ou patodiceia) do mal radical, da dor e dos sofrimentos de todo tipo, assim como a impossibilidade de qualquer felicidade autêntica e duradoura. [...] o egoísmo é a Haupt und Grundtriebfeder, motivação principal e fundamental das ações, que é instrumentalizada pela racionalidade humana (DEBONA, 2013, p. 19).

Nesse cenário, podemos dizer, de servidão à vontade, a satisfação de um desejo não representa o cessar do querer; pelo contrário, como surgem novos fins a serem perseguidos, não podemos eliminar o sofrimento de modo absoluto. Sendo assim, o reconhecimento do nosso estado de padecimento, como seres desejantes e carentes, pode ser considerado o primeiro elemento fundamental para compreender o pessimismo de Schopenhauer. A sua radicalidade, no entanto, não deriva apenas da consciência das mutações e variações no domínio do querer e nem mesmo de nossa essência como impulso constante por afirmação e satisfação. Schopenhauer complementa o quadro pessimista mostrando que, mesmo que nossos desejos sejam satisfeitos, mesmo quando obtemos regularmente o que queremos, isso não nos livra do espectro do tédio, a condição na qual sentimos uma carência ou falta que nos impele a agir. Conforme Janaway:

Nós não escolhemos viver ou ter essa natureza essencial de todos os seres vivos: de querer infindavelmente e estar infinitamente exposto ao sofrimento. Nosso sofrimento nem mesmo tem um ponto final redentor. Nossa existência e a existência do mundo, que frustram facilmente nossas aspirações, não foram concebidas para permitir o alcance de qualquer bem, nem somos capazes de fazer qualquer progressão em direção à perfeição. Nessa parte fundamental da filosofia do valor de Schopenhauer, que tem a ver com a vontade como essência do eu e do mundo, nós descobrimos, em última instância, que nada há além de uma ausência de valor. Algo é bom somente se satisfaz a vontade de algum ser, mas não pode haver nenhuma satisfação da vontade como tal e, dessa forma, nenhum bem absoluto (JANAWAY, 2009, p. 2). 
Essa é a base fundamental do pessimismo schopenhaueriano. Como pode ser percebido, ele resulta do reconhecimento que, na ordem natural do ser ou da realidade e do eu, tal como seu sistema nos ensina a ver, em um primeiro momento, não existe nenhum estado de perfeição ou quietude, tal como postulado por boa parte da tradição filosófica. A vida é, em essência, um movimento infinito em busca de completude ou realização, mas essa realização encontra-se submetida à vontade insaciável, sendo, deste modo, sempre refém da afirmação da Vontade. $\mathrm{O}$ sofrimento é contínuo ${ }^{20}$, seja por conta da falta, seja por conta do tédio. Como Schopenhauer afirma, de modo categórico:

[...] a priori, a vida humana não é suscetível de uma autêntica felicidade, atendendo ao conjunto de sua essência, senão que esta pode ser melhor descrita como um sofrimento polimórfico e um estado mental em absoluto desejável, um estado cujo objetivo não seria o de nos fazer felizes e ao que o caberia melhor o qualificativo de desventurado (SCHOPENHAUER, 2010, p. 68).

A vida humana, dentro do plano da afirmação da vontade, oscila entre dois estados. Se, por um lado, a satisfação é considerada como negativa, pois representa apenas uma ausência de dor, onde adquirimos conhecimento dessa condição de maneira mediata, isto é, através do aprazimento causado pelo extermínio de um determinado desejo; por outro lado, no que diz respeito à dor, ela é positiva. O que de fato diferencia o primeiro estado (da ausência da dor) desse último (da presença da dor), é que esse último é acessado de modo imediato:

\begin{abstract}
A única coisa que nos é dada originária e imediatamente é a carência, isto é, a dor. Mas a libertação e o prazer podem ser conhecidos por nós de forma mediata, através da evocação da aflição e da necessidade passadas, cuja desaparição propiciou sua entrada em cena. A isso se deve que não internalizemos nem estimemos cabalmente aqueles bens e vantagens em cuja possessão nos encontramos, e não pensemos senão que são como devem ser, dado que não nos fazem felizes, senão de uma maneira negativa, fazendo retroceder ao valor, pois a carência, a necessidade e a aflição constituem o único dado positivo que se nos brinda de maneira imediata, e a partir do qual se esclarecem os distintos fenômenos do espírito humano (SCHOPENHAUER, 2001, p. 63).
\end{abstract}

O ser humano, como se pode depreender daqui, é fruto da Vontade cega, irracional e "esfomeada" 21 é dor e uma dor que se manifesta individualmente através da personificação de um egoísmo imensurável ${ }^{29}$ :

O homem faz de si mesmo o centro do universo, antepondo a própria existência e o bem-estar a tudo o mais, sim, do ponto de vista natural está preparado a sacrificar qualquer coisa, até mesmo a aniquilar o mundo, simplesmente para conservar mais um pouco o próprio si mesmo, esta gota no meio do oceano (SCHOPENHAUER, 2005, p. 426-427). 
Nessa caracterização da nossa condição, o sofrimento e o egoísmo não são apenas um mero componente da nossa existência, mas algo inerente ao próprio ser. Esse quadro pessimista corresponde à nossa condição natural cotidiana e responsável pela onipresença do egoísmo. Porém, ele não é apenas uma entre as motivações, mas sim a que é mais regular nas práticas humanas e, justamente por essa razão, a motivação que está mais próxima da nossa condição. Deste modo, o egoísmo não é somente o impulso da existência e de bem-estar, mas também envolve uma disposição que abarca um modo de conceber o mundo que Schopenhauer considera como sendo "o erro fundamental". Tal erro nada mais é do que o olhar sobre o princípio de individuação, isto é, marcado pela pluralidade de indivíduos.

Podemos afirmar, nesse sentindo, que não há um espaço comum com os outros indivíduos, mas somente uma gama de indivíduos que se mostram completamente diferentes dele. Este é o cenário do mundo como representação. Aqui encontramos o modo de conhecimento próprio ao egoísmo, que transparece no mundo encoberto pelo véu de maia, o mundo regido pelo princípio de individuação. O egoísmo origina toda competição que se expressa no antagonismo interno da vontade de viver consigo mesma. A engrenagem do egoísmo pode ser compreendia através da multiplicidade que a vontade se manifesta (devido ao principium individuationis). Para essa manifestação, o indivíduo precisa apenas de si mesmo, visto que cada um é "portador da totalidade do mundo objetivo". A existência de tudo que lhe é externo se concretiza somente devido a sua representação. Como consequência disso,

[...] cada indivíduo é feito, e assim se considera a si mesmo, a totalidade da vontade de viver ou a perspectiva do mundo mesmo, ao tempo que também se tem pela condição suplementária do mundo como representação; por conseguinte, como um microcosmo tão estimável como o macrocosmo. A natureza mesma, sempre e em toda parte verdadeira, o proporciona originariamente e à margem de toda reflexão este conhecimento tão sensível como apoditicamente certo (SCHOPENHAUER, 2011, p. $85)$.

A forma do egoísmo envolve um ver como; ele configura o sujeito no modo da representação. A famosa expressão de Hobbes (bellum omnium contra omnes), máxima expressão do egoísmo, expressa a natureza e força do impulso individual, que sempre quer afirmar a si mesmo, ainda que destruindo a vida do outro: "tudo isso mostra como cada um de nós, não só tentamos tirar o que o outro quer, mas muitas vezes chegamos a destruir tudo o que ele tem até mesmo a sua vida para aumentar o nosso próprio bem-estar" (SCHOPENHAUER, 2010, p. 87). O egoísmo, como expressão interna da vontade, é tomado por Schopenhauer como algo natural e comum no mundo. Schopenhauer assume um tipo de egoísmo volitivo que impede uma operação da razão prática no nível metafísico, restringindo, deste modo o papel da 
razão na ação moral, dando ênfase em uma fundamentação da moral não com base racional, mas metafísica, a partir da concepção de compaixão. 


\section{Notas:}

${ }^{1}$ Mestre em Filosofia pelo Programa de Pós-Graduação em Filosofia da Universidade Federal de Santa Maria (UFSM), Santa Maria, R.S., Brasil. Doutoranda em Estudos Literários pelo Programa de Pós-Graduação da Universidade Federal de Santa Maria. E-mail: monica.dalcol@hotmail.com

2 Professor Associado I no Departamento de Letras Vernáculas da Universidade Federal de Santa Maria (UFSM), Santa Maria, R.S., Brasil. Bolsista de Produtividade em Pesquisa do CNPq. E-mail: anselmoperesalos@gmail.com

${ }^{3}$ Essa proposta de uma filosofia que contemple a ética e a metafísica é concretizada posteriormente no livro IV de $O$ Mundo como Vontade e Representação, em que Schopenhauer apresenta a via da negação da Vontade como "renúncia ética". É através da negação (momentânea) da vontade pela compaixão (ética) que se abre o caminho para a via ascética: a renúncia total da vontade (metafísica).

${ }^{4}$ Com relação à unidade presente em toda sua filosofia, chamado de pensamento único, pode ser visto na própria organização de sua grande obra $O$ Mundo como Vontade e Representação. O que chamamos de "princípio da unidade" tem sido enfatizado entre os principais intérpretes de Schopenhauer. Cartwright, em particular, tem sugerido que a significação moral do mundo é um problema predominante em Schopenhauer, e que ele esteve, primeiro e antes de tudo, interessado em questões morais e alega que sua "filosofia foi motivada por questões e interesses éticos do início ao fim" (CARTWRIGHT, 2006, p. 252). De fato, o próprio Schopenhauer estabeleceu que "admitir que o mundo tenha apenas um significado fisico e nenhum significado moral constitui o maior, o mais pernicioso, o erro fundamental, a própria perversidade do ânimo, e no fundo é aquilo que a fé personificou como anticristo. Não obstante, a despeito de todas as religiões que em sua totalidade afirmam o contrário disso, buscando fundamentá-lo à sua maneira mítica, este erro fundamental nunca desaparece completamente da Terra, mas ergue sempre, de tempos em tempos, novamente sua cabeça até que a indignação geral lhe obriga a esconderse" (SCHOPENHAUER, 2013, p. 39).

${ }^{5}$ Como afirma Bossert, "a Vontade é o grande demiurgo; ela é o artesão do universo em sua totalidade e a faculdade primária em cada indivíduo; ela é a criadora do corpo que ela anima” (2012, p. 24).

6 “ O fracasso da filosofia até aqui é necessário e explicável pelo fato de que, ao invés de se restringir à compreensão profunda do mundo dado, ela logo quer ir além e procura encontrar os fundamentos últimos de todo o existente, as relações eternas das coisas, o que nosso intelecto é incapaz de pensar. Sua força de apreensão só é apropriada para aquilo que os filósofos chamaram ora de coisas finitas, ora fenômenos, em suma, para as figuras fugazes desse mundo e aquilo que serve para nossa pessoa, nossas finalidades e nossa conservação; ele é imanente. Por isso sua filosofia deve também ser imanente e não se elevar a coisas sobrenaturais, mas limitar-se a entender a fundo o mundo dado, que já oferece matéria suficiente" (SCHOPENHAUER, 2013, p. 130-131).

7 “Justificar a razão como secundária em relação ao entendimento e à Vontade. Eis um dos grandes propósitos da visão de mundo (Weltanshauung) de Schopenhauer, que surgiu como uma tentativa de inversão na ordem das prioridades e, em verdade, tornou-se o "distintivo" desta filosofia ao longo da História da Filosofia do Ocidente. Até a recepção do pensamento de Schopenhauer, na última fase de sua produção, que devido ao predomínio de outras visões de mundo vigentes naquela época demorou mais de trinta anos para obter expressividade, a maioria das concepções filosóficas tomava a razão como soberana do mundo, caso do racionalismo de Descartes, do idealismo de Hegel, de Schelling e de Fichte e do esclarecimento de Kant. Quando a Vontade de $O$ mundo como vontade e representação destoou desta tradição, emergiu com ela a semente que espalharia a consideração de que, antes de um que pensa, o ser humano é um animal que quer" (DEBONA, 2010, p. 23).

8 “A representação pressupõe o envolvimento simultâneo das noções de sujeito e objeto, o que significa dizer que, ao se pensar no sujeito, logo se nota que tal noção envolve também a de objeto. E vice-versa, quando se pensa no objeto, automaticamente já temos de pensar no sujeito [...]. Estamos diante do amálgama teórico que nenhum corte, nenhum raciocínio lógico consegue separar" (BARBOZA, 1997, p. 29).

9 “Em um mundo assim, onde não é possível qualquer estabilidade, qualquer que seja, nenhum estado duradouro, mas tudo está imerso em um turbilhão e mudança incessantes, onde tudo se apressa, voa, ficar em pé na corda através de um movimento contínuo para a frente, nem se pode conceber uma vez se quer a felicidade alguma. Não se pode viver onde se encontra o "contínuo vir a ser e nunca ser" de Platão" (SCHOPENHAUER, 2009, p. 796). 
${ }^{10}$ Podemos dizer, de modo simplificado, que o princípio de razão suficiente é, segundo Schopenhauer, "a forma de todo objeto, o modo universal de sua aparição fenomênica" (2013, p. 60). Ambos os conceitos foram apresentados e analisados detalhadamente na tese doutoral de Schopenhauer, intitulada A quádrupla raiz do principio de Razão suficiente (1813). Não temos como propósito analisarmos detalhadamente esses conceitos, mas apenas apresentá-los com vistas a facilitar a compreensão do conceito de representação.

11 "Que a existência humana deva ser algo como um extravio fica suficientemente claro através da simples observação de que o homem é a concreção de carências cuja satisfação dificilmente alcançável nada lhe garante senão um estado sem dores, no qual só lhe resta o tédio e que prova que a existência em si mesma não tem nenhum valor; pois o tédio nada mais é que o sentimento de sua vacuidade" (SCHOPENHAUER, 2012, p. 141).

${ }^{12}$ A vontade, como afirma Aramayo (2012), é o coração do universo ou o grande demiurgo nas palavras de Bossert.

13 “A essência íntima do mundo, a coisa-em-si, é a vontade, a vontade de viver, e esta, enquanto tal, conta com três propriedades metafísicas: a unidade, a infundamentabilidade, e a incognoscibilidade" (SCHOPENHAUER, 2001, p. 117).

14 A ação é sempre realizada a partir do confronto do caráter com os motivos, conhecido por nós somente a posteriori, mediante a reflexão da experiência. A priori, diz Schopenhauer, "segundo o sentimento originário", nos consideramos livres, "inclusive nas ações particulares, no sentido de em qualquer caso ser possível qualquer ação" (SCHOPENHAUER, 2005, p. 374).

15 “Ora, a compreensão corriqueira confunde isso com a proposição de que ela, num dado caso, também pode desejar o oposto, e dá a isso o nome de liberdade da vontade. Mas a questão de saber se, num dado caso, a pessoa pode desejar ter [vontade de] tanto uma como a outra coisa... requer uma investigação mais aprofundada do que a acessível à decisão da mera consciência” (SCHOPENHAUER, 1985, p. 23).

${ }^{16}$ Aqui é onde propriamente Schopenhauer apresenta uma "terapia de vida contra os males do viver", apresentando suas máximas sapiencias que auxiliam o ser humano na busca do "bem viver" (viver do modo menos infeliz possível). Mencionamos o caráter adquirido, porém, não nos deteremos na sua análise, visto que o que nos interessa aqui é propriamente a fundamentação da ética, não a parte da filosofia schopenhaueriana que se detém na "sabedoria de vida". Para maiores informações sobre a temática, verificar a conceitualização de "razão prática" como "sabedoria de vida" presente especialmente na seção 16 e 55 (no conceito de caráter adquirido) em $O$ Mundo como Vontade e como Representação, e posteriormente, também, no ensaio Aforismos para a sabedoria de vida.

17 Já na sua grande obra, a referência à Kant aparece no parágrafo 55: "Foi Kant, todavia, cujo mérito a este respeito é em especial magnânimo, o primeiro a demonstrar a coexistência dessa necessidade com a liberdade da Vontade em si, exterior ao fenômeno, estabelecendo a diferença entre caráter inteligível e empírico, a qual conservo por inteiro, conquanto o primeiro é a Vontade como coisa-em-si a manifestar-se em fenômeno num determinado indivíduo e num determinado grau, já o segundo é este fenôneno mesmo tal qual ele se expõe no modo de ação segundo o tempo, e já na corporização segundo o espaço" (SCHOPENHAUER, 2005, p. 375).

18 “Tese: a causalidade segundo as leis da natureza não é a única de onde podem ser derivados os fenômenos do mundo no seu conjunto. Há ainda uma causalidade pela liberdade que é necessário admitir para os explicar (B 472). Antítese: não há liberdade, mas tudo no mundo acontece unicamente em virtude das leis da natureza (B 473)" (KANT, 1994, p. 406-407).

19 "Kant argumenta mostrando que, se não houvesse distinção, o mecanismo natural não sofreria nenhuma exceção e não se poderia atribuir qualquer liberdade, como, por exemplo, dizer da alma humana que ela seria livre. Assim, a liberdade da vontade só se torna pensável se se tomar "alma” em "dupla significação", introduzindo-se, pois, uma exceção de direito à lei da causalidade que impera no âmbito da experiência” (CACCIOLA, 1994, p. 45).

20 " [...] nada mais pode ser declarado como o objetivo de nossa existência, exceto o conhecimento de que seria melhor para nós não existir"' (SCHOPENHAUER, 2005, p. 350).

21 “Que a existência humana deva ser algo como um extravio fica suficientemente claro através da simples observação de que o homem é a concreção de carências cuja satisfação dificilmente alcançável nada lhe garante senão um estado sem dores, no qual só lhe resta o tédio e que prova que a existência em si mesma não tem nenhum valor; pois o tédio nada mais é que o sentimento de sua vacuidade" (SCHOPENHAUER, 2012, p. 142). Em outro momento, ele também afirma: “em geral, tal como recusamos um medicamento amargo, resistimos ante à ideia de 
que a dor é consubstancial à vida e de esta não aflui em nós desde o exterior, senão que cada qual leva dentro de si a inesgotável fonte de si mesmo. Mais, preferimos buscar, a modo de subterfúgio, uma causa externa dessa dor que nunca nos abandona. Infatigavelmente, vamos de desejo em desejo e, mesmo quando a satisfação alcançada não nos satisfaz tanto quanto augurávamos, caindo, na maioria das vezes em um erro vergonhoso, não nos damos conta de que tentamos abastecer o navio das Danaides... Um caso muito incomum, que pressupõe uma certa força de caráter é encontrarmos um desejo que, à vista das circunstâncias, não podemos satisfazer, mas ao que tampouco sabemos renunciar; deste modo, encontramos, de alguma maneira, o que buscávamos, a saber, algo que não podemos incriminar em todo momento como fonte de nosso pensar, em vez de reconhecer que tal fonte não é outra que nosso próprio ser; deste modo, ficamos inimigos de nossa sina, mas reconciliados com nosso ser e existir; pois com isso se relega o reconhecimento de que tanto nosso ser como nosso existir mesmos resultam circunstanciais ao padecer e que a verdadeira satisfação não é de todo impossível. A consequência deste processo é um humor melancólico que assume uma única grande dor e despreza todas as penas ou alegrias de menor magnitude. Isto constitui uma manifestação mais digna que a constante busca de miragens renovadas, bem representativa do habitual estado de coisas" (SCHOPENHAUER, 2001, p. 61-62). 


\section{Referências bibliográficas}

BARBOZA, J. Schopenhauer: a decifração do enigma do mundo. São Paulo: Moderna, 1997.

BEAUCHAMP, T. e CHILDRESS, J. Princípios de ética biomédica. São Paulo: Loyola, 1998.

RORTY, Amelie Oksenberg. Explaining Emotions. Berkeley: University of California Press, 1980.

BLUM, L. Moral Perception and Particularity. New York: Cambridge University Press, 1994.

BOSSERT, A. Introdução a Schopenhauer. Rio de Janeiro: Contraponto, 2011.

CACCIOLA, M. Schopenhauer e a questão do dogmatismo. São Paulo: EDUSP, 1994.

CARDOSO, R. A ideia de justiça em Schopenhauer. Belo Horizonte: Argvmentvm, 2008.

CARTWRIGHT, D. Historical Dictionary of Schopenhauer's Philosophy. Oxford: Scarecrow Press, 2005.

DEBONA, V. Schopenhauer e as formas da razão. São Paulo: Annablume, 2010.

DEBONA, V. A outra face do pessimismo: entre a radicalidade ascética e sabedoria de vida. Tese de doutorado. São Paulo, Programa de Pós-Gradução em Filosofia, USP, 2013. 270p.

HELD, V. The Ethics of Care: Personal, Political, and Global. New York/Oxford: Oxford University Press, 2006.

HOBBES, T. Leviatã. São Paulo: Martin Claret, 2005.

HOFFMANN, M. Empathy and Moral Development: Implications for Caring and Justice. Cambridge: Cambridge University Press, 2001.

IRWIN, T. The Development of Ethics: a historical and critical study. Oxford: Oxford: University Press, 2009.

JANAWAY, C. Schopenhauer. Trad. Adail Ubirajara Sobral. São Paulo: Edições Loyola, 2003.

JANAWAY, C. Self and World in Schopenhauer's Philosophy. Oxford: Claredon Press, 1989.

KANT, I. Fundamentação da metafísica dos costumes. Trad. Guido Antônio de Almeida. São Paulo: Barcarolla e Discurso Editorial, 2010.

KANT, I. Crítica da razão pura. Trad. Manuela Pinto dos Santos. Lisboa: Fundação Calouste Gulbenkian, 1994.

RACHELS, J. Os elementos da Filosofia Moral. São Paulo: Manole, 2006. 
ROGER, Alain. Vocabulário de Schopenhauer. Trad. Claudia Berliner. São Paulo: Martins Fontes, 2013.

SCHOPENHAUER, Arthur. O mundo como vontade e como representação. Trad. Jair Barbosa. São Paulo: Edunesp, 2005.

SCHOPENHAUER, Arthur. Sobre o fundamento da moral. Trad. Maria Lúcia Oliveira Cacciola. São Paulo: Martins Fontes, 2001.

. Metafisica de las costumbres. Trad. Roberto Rodríguez Aramayo. Madrid: Editorial Trotta SA, 2001.

. Manuscript Remains in Four Volumes. Ed. Arthur Hübscher, translated by E. F. J. Payne. Oxford: Berg, 1988-1990 (Four volumes).

. Parerga y Paralipómena. Madrid: Valdemar Letras Clásicas, 2009.

. Sobre a filosofia e seu método. Trad. Flamarion C. Ramos. São Paulo: Hedra, 2013.

. Sobre a Ética. Trad. Flamarion C. Ramos. São Paulo: Hedra, 2012.

. Schopenhauer. Trad. Wolfgang Maar, Maria Lúcia Mello e Oliveira e Cacciola. São Paulo: Nova Cultural, 1999. (Coleção Os Pensadores).

2002 .

Aforismos para a sabedoria de vida. Trad. Jair Barboza. São Paulo: Martins Fontes,

On the Freedom of the Will. Trad. K. Kolenda. Oxford: Oxford UP 1985.

. Fragmentos sobre a História da Filosofia, precedido de Esboço de uma História da Doutrina do Ideal e do Real. Trad. Karina Jannini. Prefácio de Jair Lopes Barboza. São Paulo: Martins Fontes, 2007.

2007.

Los dos problemas fundamentales de la Ética. Madrid: Siglo XXI de España Editores,

. El Mundo como Voluntad y Representación, $2^{\circ}$ Tomo (complementos). Madrid: Editorial Trotta SA, 2005.

SPIERLING. Arthur Schopenhauer. Trad. José Antonio Molina Gómez. Madrid: Herder, 2010. 